\title{
COVID-19 ARDS: Can Systemic Oxygenation Utilization Guide Oxygen Therapy?
}

\author{
Shrikanth Srinivasan ${ }^{1} \odot$, Alok K Panigrahy ${ }^{\circledR}$ \\ Keywords: COVID-19, COVID-19 patient, Critically ill adults. \\ Indian Journal of Critical Care Medicine (2021): 10.5005/jp-journals-10071-23740
}

Coronavirus disease-2019 (COVID-19) can cause acute respiratory failure with persistent hypoxemia. In the subset of patients who develop acute respiratory distress syndrome (ARDS) and progress onto mechanical ventilation, the morbidity and mortality are very high. COVID-19-induced lung disease is an unusual cause of respiratory failure and behaves differently to the ARDS due to other causes. These patients often require prolonged duration of mechanical ventilation and oxygen therapy, both of which carry their own risk. It remains unclear about the best target oxygen administration in classical ARDS or the subgroup of a patient with COVID-19-induced lung injury.

Oxygen is essential for aerobic metabolism and sustaining organ function and hypoxia is harmful, so in theory, more should be better. However, when it comes to oxygen therapy, more is not necessarily better as we do not normally exist in anhyperoxygenated state, and oxygen therapy is not without harm. Hyperoxia could lead to vasoconstriction, free radical generation, and consequent tissue damage, and denitrogenation of the lungs with resulting atelectasis and de-recruitment. Therefore, the efforts are on to find the balance, the sweet spot, for oxygenation targets.

Various trials have yielded conflicting results for optimal oxygen target for ARDS. The National Heart, Lung, and Blood Institute ARDS Clinical Trials Network had recommended a target $\mathrm{PaO}_{2}$ between $55 \mathrm{~mm} \mathrm{Hg}$ and $80 \mathrm{~mm} \mathrm{Hg}$.

However, in a recent multicenter randomized, liberal, or conservative oxygen therapy for acute respiratory distress syndrome trial $\left(\mathrm{LOCO}_{2}\right){ }_{1}^{1}$ enrolled 205 adult patients who were intubated and receiving mechanical ventilation for less than 12 hours. The $\mathrm{PaO}_{2}$ target for the conservative group was between $55 \mathrm{~mm} \mathrm{Hg}$ and $70 \mathrm{~mm} \mathrm{Hg}\left(\mathrm{SpO}_{2}\right.$ target 88-92\%) vs the liberal oxygen therapy group where target $\mathrm{PaO}_{2}$ was between $90 \mathrm{~mm} \mathrm{Hg}$ and $105 \mathrm{~mm} \mathrm{Hg}\left(\mathrm{SpO}_{2}>96 \%\right)$. They found that there is no difference in 28 days mortality from any cause between the two groups, however, the 90 -day mortality was more in the conservative group and the conservative group has more mesenteric ischemic events. Another trial, the ICU-ROX, ${ }^{2}$ was a multicenter study that included approximately 1000 patients randomized into two groups. In both groups, the lower limit of saturation was $90 \%$, conservative oxygen group the target $\mathrm{SpO}_{2}$ is $90-97 \%$ with titration of $\mathrm{FiO}_{2}$ to maintain this range vs liberal oxygen group where there was no upper limit of oxygen saturation. They found no difference in ventilator-free days at 28 days between the two groups.

Whereas, the Oxygen-ICU trial ${ }^{3}$ which included 480 patients with an expected intensive care unit length of stay of 72 hours or longer, a conservative protocol for oxygen supplementation $\left(\mathrm{SpO}_{2}\right.$ 94-98\%) was associated with an absolute risk reduction
${ }^{1}$ Department of Critical Care Medicine, Manipal Hospitals, Dwarka, New Delhi, India

${ }^{2}$ Department of Critical Care Medicine, IMS and SUM Hospital, Bhubaneswar, Odisha, India

Corresponding Author: Shrikanth Srinivasan, Department of Critical Care Medicine, Manipal Hospitals, Dwarka, New Delhi, Phone: +91 1244030723, e-mail: srinivasan.shrikanth@gmail.com

How to cite this article: Srinivasan S, Panigrahy AK. COVID-19 ARDS: Can Systemic Oxygenation Utilization Guide Oxygen Therapy? Indian J Crit Care Med 2021;25(2):115-116.

Source of support: Nil

Conflict of interest: None

for intensive care unit mortality of $8.6 \%$ compared with that for patients treated with conventional therapy $\left(\mathrm{SpO}_{2}\right.$ 97-100\%). There was also fewer incidence of shock, liver failure, and bacteremia in the conservative group. In a post hoc analysis, they found that there are less in-hospital mortality and more mechanical ventilation-free hours in the conservative oxygen group.

In a large systemic review and meta-analysis (IOTA), ${ }^{4} \mathrm{Chu}$ et al. analyzed $25 \mathrm{RCT}$ and included 16037 patients. They found that there is a significant increase in the hospital mortality and 30-day mortality in the liberal oxygen group (target $\mathrm{SpO}_{2}>96 \%$ ) and concluded that supplemental oxygen might become unfavorable above a $\mathrm{SpO}_{2}$ range of $94-96 \%$.

So given the conflicting results, the general conclusion maybe to avoid extremely low (88\%) or high (>96\%) saturation and keep the target between $90 \%$ and $96 \%$ in patients with ARDS.

Coming to COVID-19 ARDS, hypoxia in COVID-19 infection is likely of multifactorial origin. The unique pathophysiologic mechanisms include relatively preserved lung compliance, lack of excessive dead space, presence of intra-pulmonary shunting, deranged hypoxemic vasoconstriction, and silent hypoxia, frequently termed happy hypoxia wherein patients initially do not complain of dyspnea as there is no concomitant elevation of $\mathrm{PaCO}_{2}$ and/or work of breathing. The $\mathrm{PaO}_{2} / \mathrm{FiO}_{2}$ ratio remains low in COVID-19 until critical respiratory insufficiency occurs. The pathological shift to typical ARDS occurs as pulmonary circulation is progressively impaired due to thromboembolic phenomena and inflammation progressively affects alveolar-capillary cell membrane integrity producing inflammation, edema, and lung cell necrosis. ${ }^{5,6}$

SARS-CoV-2 virus enters the body via the ACE-2 receptor. Angiotensin II has proliferative, hypertrophic, and fibrotic effects

() Jaypee Brothers Medical Publishers. 2021 Open Access This article is distributed under the terms of the Creative Commons Attribution 4.0 International License (https://creativecommons.org/licenses/by-nc/4.0/), which permits unrestricted use, distribution, and non-commercial reproduction in any medium, provided you give appropriate credit to the original author(s) and the source, provide a link to the Creative Commons license, and indicate if changes were made. The Creative Commons Public Domain Dedication waiver (http://creativecommons.org/publicdomain/zero/1.0/) applies to the data made available in this article, unless otherwise stated. 
and there is upregulation of the ACE-2 receptor on exposure to hypoxia which can lead to more severe disease. Indeed, delayed identification of hypoxia in pneumonia is associated with increased disease severity, increased rate of mechanical ventilation, and increased mortality.

So, what should be the ideal oxygen target in COVID-19? Different countries have different national guidelines for oxygen targets for COVID-19 ARDS. In the UK the target $\mathrm{SpO}_{2}$ for the commencement of oxygen therapy is $91 \%$ and $94 \%$ in Singapore. They have found that the case fatality rate in Singapore is $0.08 \%$ and in the UK it is $13.4 \%$. So, improving supplemental oxygen is likely to reduce mortality in COVID-19 pneumonia.

Surviving sepsis guideline for COVID-19 pneumonia suggests starting supplemental oxygen if the $\mathrm{SpO}_{2}$ is less than $92 \%$ and recommended to start supplemental oxygen if the $\mathrm{SpO}_{2}$ is less than $90 \%$. They recommended to target $\mathrm{SpO}_{2}$ should not be more than $96 \%$.

Although monitoring the saturation and keeping the targets between $90 \%$ and $96 \%$ are practical and widely applicable. Does this translate to adequate oxygenation at the level of the tissues?

The authors show in their small hypothesis-generating study that calculating the oxygen extraction ratios $\left(\mathrm{O}_{2} \mathrm{ER}\right)$ by simultaneously measuring the arterial blood gas, central venous blood gas, and central venous $\mathrm{O}_{2}\left(\mathrm{ScVO}_{2}\right) . \mathrm{O}_{2} \mathrm{ER}$ is the fraction of the oxygen delivered to the capillaries that are taken up into the tissues and it is an index of the efficiency of oxygen transport. It is the ratio of $\mathrm{O}_{2}$ uptake $\left(\mathrm{VO}_{2}\right)$ to $\mathrm{O}_{2}$ delivery $\left(\mathrm{DO}_{2}\right)$; the normal ratio is $0.2-0.3$, which corresponds to a $\mathrm{ScVO}_{2}$ of $70-80 \%$.

A high $\mathrm{O}_{2} \mathrm{ER}$ (low $\mathrm{ScVO}_{2}$ ) is a feature of "flow insufficient states", secondary to anything which causes a decreased cardiac output or an increased tissue oxygen demand.

A low $\mathrm{O}_{2} \mathrm{ER}$ (high $\mathrm{ScVO}_{2}$ ) is caused due to either a decreased tissue oxygen demand, or inefficient oxygen utilization by the tissues, or pathologically and disproportionately increased cardiac output.

In their small study of eight mechanically ventilated patients with severe ARDS where the saturation targets were kept between $92 \%$ and $96 \%$ and there were no signs of anaerobic metabolism; there a good proportion of patients in which the $\mathrm{O}_{2}$ ER was reduced suggesting that systemic $\mathrm{O}_{2}$ utilization is abnormal in patients with severe COVID-19. In some patients the oxygen delivery can be excessive of the requirements and such patients may benefit from less aggressive interventions to maintain $\mathrm{SpO}_{2}$.

SARS-CoV-2 is known to affect host mitochondrial function, although there is limited data on its final influence on cellular metabolism.

This hypothesis appears attractive but would be practically difficult to perform given the need for advanced monitoring and the need to repeatedly calculate the $\mathrm{O}_{2} E R$ as in reality the oxygen extraction of each tissue fluctuates constantly and will change as the disease progresses, besides having other limitations as using $\mathrm{ScVO}_{2}$ as an acceptable surrogate for $\mathrm{SvO}_{2}$ (which is true only in certain settings).

It may have a role in patients with "happy hypoxemia", where tolerance of lower $\mathrm{SpO}_{2}$ goals based on systemic $\mathrm{O}_{2}$ utilization may be beneficial in reassessing intubation and preventing the secondary complications of mechanical ventilation. Still, as the authors have pointed out, more studies and longitudinal data analysis would be required to confirm consistency of the results obtained and before exploring the practical utility of systemic oxygenation targets to titrate oxygen therapy in COVID-19 ARDS.

In conclusion, currently, we should keep a balance between liberal oxygen therapy and conservative oxygen therapy. We should avoid hyperoxia as well as hypoxia. Target $\mathrm{SpO}_{2}$ between $92 \%$ and $96 \%$ is associated with good outcomes both in COVID-19 ARDS as well as in non-COVID ARDS.

\section{ORCID}

Shrikanth Srinivasan @ https://orcid.org/0000-0002-5336-3767

Alok K Panigrahy (i) https://orcid.org/0000-0002-2160-2305

\section{References}

1. Barrot L. Asfar P, Mauny F, Winiszewski H, Montini F, Badie J, et al. Liberal or conservative oxygen therapy for acute respiratory distress syndrome. N Engl J Med 2020;382(11):999-1008. DOI: 10.1056/ NEJMoa1916431.

2. ICU-ROX Investigators and the Australian and New Zealand Intensive Care Society Clinical Trials Group, Mackle D, Bellomo R, Bailey M, Beasley R, Deane A, et al. Conservative oxygen therapy during mechanical ventilation in the ICU. N Engl J Med 2020;382(11):989-998. DOI: 10.1056/NEJMoa1903297.

3. Girardis M, Busani S, Damiani E, Donati A, Rinaldi L, Marudi A, et al. Effect of conservative vs conventional oxygen therapy on mortality among patients in an intensive care unit: the Oxygen-ICU randomized clinical trial. JAMA 2016;316(15):1583-1589. DOI: 10.1001/ jama.2016.11993.

4. Chu DK, Kim LH, Young PJ, Zamiri N, Almenawer SA, Jaeschke R, et al. Mortality and morbidity in acutely ill adults treated with liberal versus conservative oxygen therapy (IOTA): a systematic review and meta-analysis. Lancet 2018;391(10131):1693-1705. DOI: 10.1016/ S0140-6736(18)30479-3.

5. Ghoshal AG. Hypoxemia and oxygen therapy. J Assoc Chest Physicians 2020;8(2):42-47. DOI: 10.4103/jacp.jacp_44_20.

6. Garg RK, Kimbrough T, Lodhi W, DaSilva I. Systemic oxygen utilization in severe COVID-19 respiratory failure-a case series. Indian J Crit Care Med 2021;25(2):215-218. 